http://jmscr.igmpublication.org/home/ ISSN (e)-2347-176x ISSN (p) 2455-0450 crossref DOI: https://dx.doi.org/10.18535/jmscr/v7i12.144

\title{
Comparative Study of Intrathecal $0.5 \%$ Bupivacaine and $0.5 \%$ Bupivacaine with Clonidine for Lower Abdominal Surgeries
}

\author{
Authors \\ Dr Konduru Sindhura ${ }^{1}$, Dr Kalyan Chakravarthy $\mathbf{P}^{2}$, Dr Balamurali Krishna $\mathbf{M}^{3}$, \\ Dr Madhu Chaitanya $\mathbf{M}^{4}$, Dr Sai Rupa $\mathbf{Y}^{\mathbf{5}}$ \\ 1,3,4,5 Post graduate, Department of Anaesthesiology GEMS \\ ${ }^{2}$ Professor, Department of Anaesthesiology GEMS \\ *Corresponding Author \\ Dr Konduru Sindhura
}

\begin{abstract}
Background: In the present day practice of Anesthesiology, bupivacaine is the most commonly used drug for spinal anesthesia. To improve the quality of analgesia and prolong the duration of its action, many adjuvants have been tried. Intrathecal clonidine an $\alpha 2$ adrenoceptor agonist has potent central antinociceptive properties with analgesic effect at spinal level mediated by post synaptically situated adrenoreceptor in dorsal horn of spinal cord .Low doses of clonidine have shown effectiveness in intensifying spinal anesthesia. This study was done to evaluate the efficacy of spinal anesthesia with clonidine added to hyperbaric bupivacaine in lower abdominal surgeries.

Aim: This study compared 0.5\% Bupivacaine and 0.5\% Bupivacaine with Clonidine for surgeries below the level of umbilicus under spinal anaesthesia.

Materials and Methods: A randomized prospective observational study includes 60 patients of ASA I and ASA II aged 18-60 years, scheduled for elective lower abdominal surgery under spinal anaesthesia. Patients were randomly allocated into two groups. Group B received hyperbaric bupivacaine hydrochloride $12.5 \mathrm{mg}(2.5 \mathrm{~mL})+0.5 \mathrm{ml}$ of normal saline. Group BC received bupivacaine hydrochloride $12.5 \mathrm{mg}(2.5 \mathrm{~mL})+0.5 \mathrm{ml}(25 \mu \mathrm{g})$ of preservative free clonidine. The volumes of both the groups are same (i.e $3.5 \mathrm{ml}$ ). Heart rate, NIBP, SpO2 were monitored. The onset and duration of sensory block and motor block, the highest dermatomal level of sensory block, time to complete motor block recovery and duration of spinal anaesthesia, duration of analgesia and side effects were recorded.

Results: The onset of sensory and motor blockade was faster in the BC group compared to group B. The duration of sensory and motor block were prolonged in group BC compared to group B. Decrease in the systolic blood pressure was noted in group BC. No significant hemodynamic changes were observed in both the groups.

Conclusion: Clonidine potentiates bupivacaine spinal anesthesia by increasing the duration and improving the quality of analgesia without significant hemodynamic side effects.

Keywords: spinal anesthesia, clonidine, bupivacaine.
\end{abstract}

\section{Introduction}

Spinal anesthesia was first introduced into clinical practice by Karl August Bier in $1898^{[1]}$. It is one of the most popular techniques used for both elective and emergency surgical procedures like Caesarean sections, lower abdominal surgeries, orthopedic and urological surgeries just to name a few $^{[2]}$. 
Spinal anesthesia defined as the regional anesthesia obtained by blocking nerves in the subarachnoid space. The advantages of being an awake patient, easy to perform, rapid onset of action, low cost of drug, relatively less side effects and rapid patient turnover has made this the choice of many a surgical procedure ${ }^{[3]}$.

Sometimes these advantages are offset by relatively shorter duration of action and uncomfortable postoperative period when its action wears off.

Other methods like epidural anesthesia require technical expertise, larger amount of drug usage and sometimes even ending up with failed epidural analgesia. Further, Transcutaneous electrical nerve stimulator does not stand up against drug therapies as a sole treatment for anything other than mild post operative pain.

Therefore it forms a challenging forefront in clinical and research advances, where if one can enhance sensory blockade into postoperative period by combining the lowest dose of the drugs with longer duration of action and least side effects, probably it may go a long way in alleviation of pain and suffering. Many adjuvants like opioids, clonidine, ketamine, morphine and buprenorphine etc have been added to prolong intrathecal bupivacaine action to extend intraoperative analgesia into postoperative period also. However each drug has its own limitations, and a need for alternative methods or drugs always exist ${ }^{[4]}$.

Central neuraxial opioids offer the benefit of analgesia but however the related side effects include sense of dizziness, nausea, vomiting, pruritis, urinary retention and even cases of respiratory depression have been reported ${ }^{[5]}$.

Recently clonidine, as an adjuvant has been tried to extend the action of local anesthetics .Intrathecal clonidine produces dose dependent analgesia and has been successfully used as a sole analgesic via the intrathecal route ${ }^{[6]}$.Clonidine, an alpha2 agonist, has been used effectively for the treatment of acute and chronic pain ${ }^{[7]}$. It provides analgesia of variable efficacy and duration $^{[8][9][10][11][12]}$ and to potentiate postoperative analgesia when used in combination with local anaesthetics ${ }^{[13][14][15]}$. But, clonidine also demonstrated adverse effects including sedation, hypotension and bradycardia.

On this background, this study was done to evaluate the effectiveness of adding $25 \mu \mathrm{g}$ clonidine to hyperbaric bupivacaine for spinal anesthesia and to compare it with that of bupivacaine.

\section{Materials and Methods}

After the study protocol had been approved by the Institutional review committee, informed and written consent was obtained from all the participents. A randomized comparative study was done in Department of Anaesthesiology GEMS and Hospital, Srikakulam.

\section{Inclusion Criteria}

Patients between ages 18 and 60 years scheduled for elective lower abdominal surgeries belonging to American Society of Anesthesiologists (ASA) physical status I and II.

\section{Exclusion Criteria}

Patient refusal, Emergency surgeries, patients with baseline heart rate $<60 / \mathrm{min}$, known hypersensitivity to bupivacaine, Infection at the proposed site of intrathecal injection, Bleeding disorder, neurological disease, Conversion to general anaesthesia and $\mathrm{BMI} \geq 30 \mathrm{~kg} / \mathrm{m}^{2}$.

A formula used to determine the appropriate sample size for the study showed that a minimum of 60 participants, each group comprising 30 . $(\mathrm{n}=30)$

Patients were randomly divided on alternative basis into two groups.

Group "B" Bupivacaine group- Receiving Intrathecal Bupivacaine $12.5 \mathrm{mg}(2.5 \mathrm{~mL})+0.5 \mathrm{~mL}$ normal saline. (Total $3 \mathrm{~mL}$ )

Group "BC" Clonidine group- Receiving Intrathecal Bupivacaine $12.5 \mathrm{mg}(2.5 \mathrm{~mL})+25 \mu \mathrm{g}$ clonidine. (1 $\mathrm{ml}(150 \mathrm{mcg})$ clonidine was diluted with $3 \mathrm{ml}$ Normal saline and then $0.5 \mathrm{ml}$ was taken to a total volume of $3 \mathrm{~mL}$ ).

All the patients were seen preoperatively at least one day before surgery during which they were clinically assessed and fitness for the study 
verified. All the patients were kept fasted overnight. They were also pre-medicated with oral diazepam 10mg the night before surgery and $5 \mathrm{mg}$ on the morning of surgery (about two hours before surgery).

In the operating theatre, baseline vital signs: heart rate (HR), systolic blood pressure (SBP), diastolic blood pressure (DBP) mean arterial pressure (MAP), oxygen saturation $\left(\mathrm{SpO}_{2}\right)$, electrocardiogram and temperature were recorded. A 18 gauge cannula was inserted into a forearm vein and $10 \mathrm{ml} / \mathrm{kg}$ of $0.9 \%$ saline was infused over the 15 minutes preceding the spinal anaesthesia. The spinal anaesthesia was performed under aseptic conditions at the interspace between the $3^{\text {rd }} \& 4^{\text {th }}$ lumbar vertebra with the patient in the sitting or lateral position. $3 \mathrm{ml}$ of test drug was injected through a 25-gauge quincke needle into the intrathecal space over 15 seconds. The patient was made immediately returned to the supine position.

Haemodynamic parameters such as SBP, DBP, MAP, and HR were recorded every 3 minutes for the first 15 minutes and at 5 minutes intervals until the end of the procedure.

The onset of sensory block was tested by pinprick method using hypodermic needle. The time of onset was considered from the time of injection of drug into subarachnoid space to loss of pin prick sensation.

The highest level of sensory block and time required to achieve it was noted and the time for two dermatomal segments regression of sensory level was also noted. The duration of sensory blockade was taken as time from onset to time of return of pinprick sensation to S1 (heel) dermatomal area.

Using Bromage scale Motor Blockade was assessed. The time of onset of motor blockade also noted (Br. 3). The duration of motor block was taken from time of injection to complete regression of motor block. (ability to lift the extended leg) ( $\mathrm{Br} 0)$.

Post operatively, vital signs, VAS scores and sedation scores were monitered until the sensory block regressed to $\mathrm{S} 1$ dermatome. Hypotension was defined as fall of arterial blood pressure $<20 \%$ of baseline and it was treated with Inj. Mephentermine $6 \mathrm{mg}$ intravenous increments. Bradycardia is defined as pulse rate $<60 / \mathrm{min}$ and was treated by atropine $0.6 \mathrm{mg}$ intravenous stat. Side effects like nausea, vomiting, sedation, and urinary retention were continued to monitor postoperatively.

All data were analyzed using either Student's t-test or Chi- square test. Quantitative data was analyzed by student's $t$ test and qualitative data was analyzed by Chi-square test. All values were expressed as mean \pm standard deviation. p-value $<0.05$ was considered statistically significant.

\section{Results}

There was no statistically significant difference in demographic characteristics among both the groups as shown in table 1.

Table 1: Demographic Profile

\begin{tabular}{|l|c|c|c|}
\hline Parameter & Group B & Group BC & p- Value \\
\hline Age (Years) & $42.3+10.5$ & $40.4+12.4$ & 0.43 \\
\hline Height (Ft) & $5+0.43$ & $5.53+0.32$ & 0.75 \\
\hline Weight (Kgs) & $56.7+8.4$ & $57.1+1.1$ & 0.49 \\
\hline SEX- males & 16 & 15 & \\
\multicolumn{1}{|c|}{ females } & 14 & 15 & \\
\hline
\end{tabular}

Table 2: Characteristics of Spinal Block

\begin{tabular}{|l|c|c|c|}
\hline Parameter & GROUP B & GROUP BC & p-VALUES \\
\hline Sensory block (sec) & 137.60 & 112.22 & $<0.001$ \\
\hline Onset of Motor block (sec) & 231.80 & 165.1 & $<0.001$ \\
\hline Time to peak sensory block(in min) & 11.55 & 6.93 & $<0.0001$ \\
\hline Time to 2 segment regression & $83.3 \pm 28.9$ & $139.2 \pm 30.4$ & $<0.001$ \\
\hline Time to complete sensory recovery & 212.1 & 246.8 & $<0.001$ \\
\hline Time to complete motor recovery & 193.8 & 203.5 & $<0.001$ \\
\hline Duration of complete analgesia (mins) & 165.1 & 240.2 & $<0.001$ \\
\hline Duration of effective analgesia (mins) & 212.6 & 332.64 & $<0.001$ \\
\hline Time to first pain medication (mins) & 221.4 & 362.84 & $<0.001$ \\
\hline
\end{tabular}


Heart rate was compared at various intervals and there was no statistically significant difference among both the groups at any point of time ( $p$ $>0.05$ ). only 1 patient had bradycardia after spinal anesthesia which was treated with single dose of inj. Atropine 0.6mg. Though there is a fall in SBP is more in clonidine group compared to control group, there is no significant hypotension in both the groups. There is no statistically significant difference with regard to mean arterial pressure among both the groups.

Graph 1: Mean heart rate at various intervals

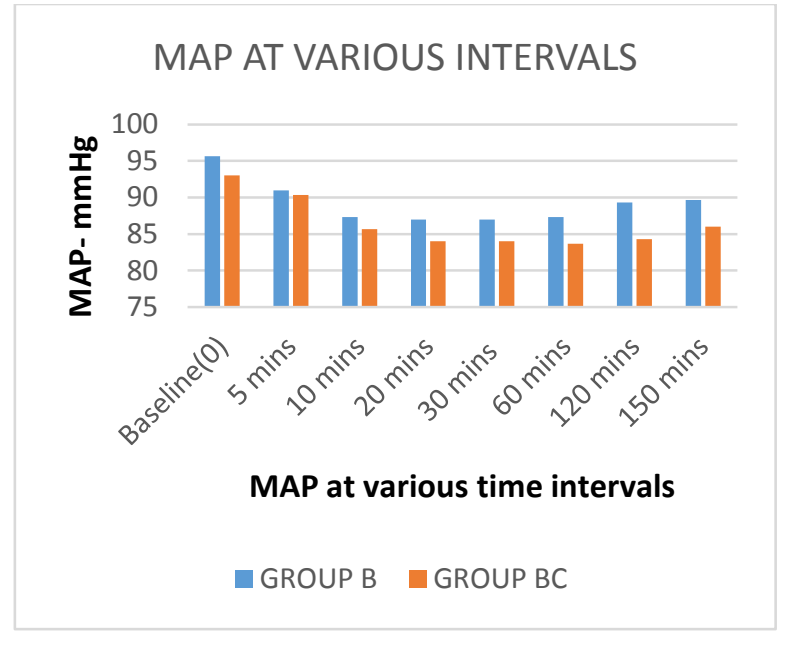

In this study we noticed 1 patients had bradycardia and 4 patients experienced sedation postoperatively in clonidine group.

Table 3: Side Effects

\begin{tabular}{|l|c|c|}
\hline Adverse effects & Group B & Group B C \\
\hline Nausea /vomiting & $0(0 \%)$ & $0(0) \%$ \\
\hline Sedation & $0(0 \%)$ & $4(12 \%)$ \\
\hline Bradycardia & $0(0 \%)$ & $1(3 \%)$ \\
\hline
\end{tabular}

\section{Discussion}

Spinal anesthesia has many potential advantages over general anesthesia, especially for operations involving the lower abdomen and the lower extremities. The duration of spinal anesthesia can be prolonged by the adjuvants like opioids, neostigmine, vasoconstrictors, midazolam, ketamine etc. Vasoconstrictors (epinephrine, ephedrine and phenylephrine) can prolong the duration of action of the local anesthetic by decreasing systemic absorption but neurological signs and symptoms have been found due to reduced blood supply to the spinal cord ${ }^{[16]}$. Intrathecal ketamine results in psychomotor symptoms, midazolam produces sedation, and neostigmine causes excessive nausea and vomiting. Clonidine is a partial agonist for $\alpha 2$ adreno receptors. It can increase both sensory and motor block of local anesthetics ${ }^{[17]}$. The analgesic effect of clonidine following its intrathecal administration is mediated spinally through activation of postsynaptic $\alpha 2$ receptors in substantia gelatinosa of the spinal cord and it works by blocking the conduction of $\mathrm{C}$ and $\mathrm{A}$ delta fibers.

This study was done to evaluate the effects of clonidine added to hyperbaric bupivacaine for spinal anaesthesia. Demographic parameters were kept identical in both the groups to avoid variations in intraoperative and postoperative outcome of patients. The type of surgeries performed were also identical in both the groups. We observed the parameters like onset of Sensory and motor blockade, Highest level of sensory blockade and Time to achieve peak sensory blockade, Time for two segment regression and Time for complete sensory and motor recovery, Duration of complete analgesia, and Time to first pain medication, and Side effects / complications associated with it.

In present study, the mean time for onset of sensory block in group BC was112.20 seconds (1.87min) and in group B is 137.60 seconds (2.29min). The mean time for the onset of motor block in group BC was 165.1 seconds $(2.75 \mathrm{~min})$ and in group B was 231.80 seconds (3.86min). This shows the onset of sensory and motor block between the groups with faster onset in group BC compared to group B is statistically significant. In a prospective randomized controlled study conducted by Gurudatta et $\mathrm{al}^{[18]}$, concluded that the mean time for the onset of sensory blockade was faster in group BC (clonidine group) $1.62 \pm 0.85 \mathrm{~min}$ compared to (bupivacaine group) $2.24 \pm 1.04 \mathrm{~min}$ in group B. Also an anotherstudy done by B.S. Sethi et $\mathrm{al}^{[19]}$, in 60 patients evaluated the effect of low dose of $1 \mu / \mathrm{kg}$, intrathecal clonidine as an adjuvant to bupivacaine 
and concluded that the onset of action was faster in clonidine group compared to bupivacaine groups. Our results are similar to this study.

The mean time taken to achieve peak sensory level in group BC compared to group B was 6.93 minutes vs 11.55 minutes $(\mathrm{p}<0.05)$ by chi square test. This implied that group BC achieved highest level of sensory block. In a study done by Dobrydnjov $^{[20]}$, concluded that the highest level of sensory analgesia wasT10in bupivacaine group,T6 in group $\mathrm{BC} 15$. Thus, the addition of clonidine to intrathecal hyperbaric bupivacaine resulted in higher level of sensory blockade and faster onset when compared to bupivacaine alone.

The time for two segment regression was also prolonged in group BC (139.2 minutes) and it is 83.3 minutes in group B. In a study done by Dobrydnjov $^{[20]}$ with different doses of clonidine, $15 \mu$ and $30 \mu$ with plain hyperbaric bupivacaine in spinal anesthesia concluded that time to 2 segment regression was less with plain bupivacaine group compared to clonidine group which was highly significant. Similarly in a study done by BS Sethi et $\mathrm{al}^{[19]}$, concluded that the mean time to two segment regression of level of sensory analgesia was significantly longer in the clonidine group than the bupivacaine group $(\mathrm{p}<0.001)$. Our results correlates with the above studies.

In present study, the time for complete sensory regression in group $\mathrm{BC}$ was prolonged by about 25 - 30 minutes (group BC-246.8 minutes, group $\mathrm{B}-212.1$ minutes). The duration of motor block in group $\mathrm{BC}$ was prolonged by about 10 minutes (groupBC-203.5 minutes, groupB-193.8 minutes) which is statistically significant $(p<0.001)$. and it is similar to a study done by Gurudutta et $\mathrm{al}^{[18]}$, B.S. Sethi et al ${ }^{[19]}$.

Clonidine produced significantly longer motor blockade. Intrathecal clonidine alone even in higher doses does not induce motor block. In contrast when combined with local anaesthetics, it can potentiates the duration and intensity of motor blockade. Hence, the use of $25 \mu \mathrm{g}$ clonidine intrathecally resulted in increased intensity, prolonged sensory and motor blockade.
We observed that the duration of complete analgesia was $240.8 \mathrm{~min}$ in group BC and 165.1 $\mathrm{min}$ in group B. The time for the first request of rescue analgesia was delayed in group BC by $140-$ 150 minutes compared to group $\mathrm{B}$, thus reducing the analgesics requirement in the early postoperative period and also the quality of analgesia was better in group BC than in group B. Similar to the studies done by Sethi et $\mathrm{al}^{[19]}$ and Strebel et al, ${ }^{[21]}$ in present study, total analgesia time was also prolonged. We observed a better quality of block in clonidine group i.e density of block is increased. These results were comparable to the study done by Dobrydnjov et al, ${ }^{[20]}$ who reported the surgeon rating of the operating conditions as excellent or good in 93\%-100\% of patients receiving $50 \mu \mathrm{g}$ clonidine with bupivacaine.

In our study there was a significant reduction in the VAS scores of the patients in clonidine group compared to patients receiving only bupivacaine in the first twelve hours post operatively which implies the better quality of analgesia postoperatively, and reduced the need of analgesics with the use of intrathecal clonidine.

In a study done by Gurudatta et al demonstrated the duration of complete analgesia with $75 \mu \mathrm{g}$ of intrathecal clonidine was $327 \mathrm{~min}$ compared to 207 minutes in bupivacaine group which was highly significant. The 6 hour postoperative requirement of diclofenac injection was less in clonidine group ${ }^{[18]}$.

Similarly in a study done by B.S. Sethi et al found out that the duration of effective analgesia was significantly prolonged with addition of clonidine (614 mins) compared to bupivacaine group (223mins). It reduced the need for intra-muscular and intravenous analgesia in the immediate postoperative period ${ }^{[19]}$. Our results are also in accordance to these studies. Hence the addition of clonidine to bupivacaine intrathecally results in significantly prolonged duration of complete analgesia, effective analgesia and the time to first rescue analgesia is also longer with improved quality of analgesia and reduced requirements of analgesics postoperatively. 
Heart rate was observed at various intervals and compared in both the groups which showed no significant difference among both the groups at any interval. SBP, DBP, and mean arterial pressures were compared at various time intervals was statistically and clinically insignificant. there is no statistically significant hypotension in clonidine group at any point of time compared to the control group which was in accordance with the findings of Strebel et al, ${ }^{[21]}$ and in contrast to the findings of B.S.Sethi et al, ${ }^{[18]}$ who used higher doses of clonidine. Thus, the cardiovascular profile of our patients was found to be remarkably stable throughout the intraoperative period in both the groups.

Many studies have conducted with bupivacaine for prolonging the post operative analgesia. B.S. Sethi et al, ${ }^{[19]}$ showed that addition of $1 \mu \mathrm{g} . \mathrm{kg}$-1 of clonidine to intrathecal bupivacaine is safe and likely to be as effective as higher dosages minimizing the side effects.

Dobrydnjov et al,20 in his study concluded that small dose of intrathecal clonidine is not usually associated with systemic side effects such as bradycardia, hypotension or sedation.

Kaabachiet al22 in his study concluded that intrathecal clonidine at $1 \mu \mathrm{g} / \mathrm{kg}$ prolonged spinal anaesthesia without causing severe adverse effects.

\section{Conclusion}

The supplementation of spinal block with a low dose of clonidine $(25 \mu \mathrm{g})$ produces a significantly shorter onset of sensory and motor block and a significantly longer sensory and motor block than bupivacaine alone. The $25 \mu \mathrm{g}$ of clonidine provides maximum benefit with minimum side effects. These doses have minimal effect on hemodymanic parameters and hence can be advocated as an adjuvant to bupivacaine in spinal anesthesia for lower abdominal surgeries. Thus a combination of local anesthetic and an alpha 2 adrenergic agonist like clonidine is used to extend pain relief well into the postoperative period.

\section{References}

1. Parameshwara G: spinal, epidural to combined spinal epidural analgesia, the history of central neuraxial block. Indian J Anaesth 2001; 45(6):406- 412.

2. Dureja G.P, JayalaxmiT.S: Colloid preloading before spinal and epidural anaesthesia. Hospital today 2000: V(11):601-603.

3. Paul G Barasch, Bruce F Collen, Clinical Anesthesia, 6thedition, Lippincort, Williams and Wilkins, 2006:700-706.

4. Poonam S Ghodki, Shalini P Sardesai ,evaluation of the effect of intrathecal clonidine to decrease shoulder pain in laparoscopy under spinal anesthesia. Indian J Anaesth2010;54(3)231-234.

5. Gustafsson LL, Schildt B, Jackobson K. Adverse effects of extra duraland intra the calopiates: report of a nationwide survey in Sweden Br J Anaesth 1982;54:479-86.

6. Eisenach JC, et al. a2-adrenergic agonists for regional anaesthesia: a clinical review of clonidine

(1984-1995). Anaesthesiology; 1996:85, 655-674.

7. Larson MD. History of anesthetic practice. In Miller'sanaesthesia. Ed by Ronald D Miller. $6^{\text {th }}$ Edn. Churchill Livingstone. 2005:3-52.

8. Goodison, R. Rand Josyala, A-Agent for spinal anesthesia -hyperbaric bupivacaine. anaesthesia; 1979;34:375.

9. Sundnes, K.O.et. etal -Spinal Analgesia with hyperbaric bupivacaine effects of volume of solution. Br. J. Anaesth, 1982;54:69-73.

10. Chambers, W.A.et al - Spinal Anesthesia with hyperbaric bupivacaine- effects of concentration and volume administered. Br.J.Anesth1982; 54:75-79.

11. Stoelting RK, Antihypertensive chapter 15. In: Pharmacology\& Physiology in Anesthetic Practice, 3rd Ed. P.305Bonnet F:1989.

12. Niemi L. Effects of intrathecal clonidine on duration of bupivacaine spinal 
anaesthesia, haemodynamic, and postoperative analgesia in patients undergoing knee arthroscopy. Acta Anaestesiological Scandinavica 1994, 38:724-728.

13. De Negri P. Sinal anesthesia with clonidine and bupivacaine in young humans: interactions and effects on the cardiovascular system. Minerva anaestesiological 1997;63:119-25.

14. Takahiko Kamibayashi, Clinical Uses of [alpha] 2-Adrenergic agonists Anesthesiology: November 2000; (93) 5 : 1345-49.

15. Chiari, et al, Analgesic and hemodynamic effects of intrathecal clonidineas the sole analgesic agent during the first stage of labor-a dose response study. Anaesthesiolog1999; 91(2):388-396.

16. De VosH. BriccaG. De Keyser J. Dc Backer J P Bousquet P. Vauquclin G Imidazoline receptors, non-adrenergic idazoxan binding sites and alpha 2adrenoceptors in the human central nervous system. Neuroscience 1994:59:589-98.

17. Roh D.-H, Kim H.-W, Yoon S.-Y, Seo, H.-S. Kwon Y.-B, Han, A. J. Beitz, and Lee J.-H. Intrathecal Clonidine Suppresses Phosphorylation of the N-Methyl-DAspartate Receptor NR1 Subunit in Spinal Dorsal Horn Neurons of Rats with Neuropathic Pain AnesthAnalg 2008; 107(2): 693 -700.

18. C.L. Gurudatta, G. Svenkatesh et al. A Prospective randomized controlled study of the effect of intrathecal clonidine with hyperbaric bupivacaine $0.5 \%$ for lower abdominal surgeries. Karnataka Anesthesia J 2008; 9(2).
19. Sethi BS, Samuel M, Sreevastava D. Efficacy of analgesic effects of low dose intrathecal clonidine as adjuvant to bupivacaine. Indian J. Anaesth. 2007; 51(5):415-419.

20. Dobrydnjov I, Axelsson K, Thorn SE, et al. Clonidine combined with small-dose bupivacaine during spinal anesthesia for inguinal herniorrhaphy: a randomized double-blinded study. Anesth Analg 2003; 96: 1496-503(s).

21. Strebel S, Jürg A. Gurzeler, Schneider m .c, Aeschbach A, Kindler c.h, Small- Dose Intrathecal Clonidine and Isobaric Bupivacaine for Orthopedic Surgery: A Dose-Response Study Anesth Analg 2004;99:1231-1238(s)

22. Kaabachi $\mathrm{O}$, et al. Clonidine $1 \mu \mathrm{g} / \mathrm{kg}$ is a safe and effective adjuvant to plain bupivacaine in spinal anesthesia in adolescents Anaesthanalg 2007;105:51619. 